\title{
ANALIZA OPTIMALNIH SLOJEVA FLEKSIBILNIH KOLOVOZNIH KONSTRUKCIJA
}

Zahid Bašić ${ }^{1}$

Nedim Suljić

UDK: $625.7 / .8$

DOI:10.14415/konferencijaGFS 2016.053

Rezime: Pri izgradnji donjeg stroja puteva, izgradnje nasipa i izgradnje hidrotehničkih objekata, potrebno je obezbijediti kvalitetno pozajmište materijala za tu namjenu. Velika industrijska postrojenja prilikom proizvodnje, stvaraju industrijski otpad koji je neophodno deponovati, a što u konačnici iziskuje i velike troškove.

Radi toga se $i$ javila ideja o istraživanju mogućnosti upotrebe industrijskog nusproizvoda pri proizvodnji sode u građevinske svrhe, izgradnji donjeg stroja puteva, nasipa ili hidrotehničkih objekata.za potrebe analize optimalnih slojeva fleksibilnih kolovoznih konstrukcija izvršeno je istraživanje na modelu dimenzioniranom prema važećoj metodi dimenzioniranja datoj u smjernicama za projektovanje, građenje, održavanje i nadzor na putevima (knjiga I, dio I, poglavlje 7).

Analizom je obuhvaćena izvedba donjeg stroja za tri odabrane recepture. Kolovozne konstrukcije prema važećoj metodi, a koje se izvode na donjem stroju za tri odabrane recepture, dimenzionirane su $i$ analizirane $u$ radu.

Ključne riječi: donji stroj, analiza, kolovozna konstrukcija, metoda, dimenzioniranje

\section{UVOD}

Proces proizvodnje u mnogim velikim industrijskim pogonima često podrazumijeva stvaranje otpadnog materijala koji je neophodno deponovati. U industrijskoj proizvodnji sode stvara se otpadni materijal, tzv. "krečni mulj" koji se sistemom cjevovoda pomiješan sa vodom transportuje do mjesta gdje se vrši taloženje materijala. Nakon taloženja krečnog mulja na dnu taložnice sa površine se višak vode ispušta u prirodni vodotok. Pored krečnog mulja u procesu proizvodnje sode upotrebljava se velika količina uglja za stvaranje pare. Kao posljedica upotrebe velike količine uglja javlja se još jedan otpadni materijal, a to je elektrofilterski pepeo. [1] [3]

Iz gore navedenih razloga, izvršeno je ispitivanje mogućnosti upotrebe ova dva otpadna materijala za izgradnju donjeg stroja puteva, željeznica, izgradnju nasipa, brana i inače za upotrebu u građevinske svrhe.

\footnotetext{
${ }^{1}$ Prof. dr. sc. Zahid Bašić, dipl. ing. građ., Univerzitet u Tuzli, Rudarsko-geološko-građevinski fakultet, ul. Tihomila Markovića br. 1, 75000 Tuzla, mob.: 0038761136751,e-mail: mido_basic@ hotmail.co.uk

2 Prof.dr.sc. Nedim Suljić dipl. ing. građ., Univerzitet u Tuzli, Rudarsko-geološko-građevinski fakultet, ul. Tihomila Markovića br. 1, 75000 Tuzla
} 
Contemporary achievements in civil engineering 22. April 2016. Subotica, SERBIA

U ovom radu je za potrebe uporedne analize izvršeno dimenzioniranje slojeva fleksibilne kolovozne konstrukcije prema važećoj metodi datoj u Smjernicama za projektovanje, građenje, održavanje i nadzor na putevima (Knjiga I, Dio 1, Poglavlje 7), gdje su posebno tretirana tri slučaja izvedbe donjeg stroja puteva:

1.Kolovozna konstrukcija na posteljici izrađenojod materijala spravljenog po recepturi :50 \% "crno more" i 50 \% "bijelo more ",

2. Kolovozna konstrukcija na posteljici izrađenoj od materijala spravljenog po recepturi: $30 \%$ "crno more", 40 \% "bijelo more " i $30 \%$ kameni agregat 0-31,5 mm,

3.Kolovozna konstrukcija na posteljici srednjeg kvaliteta izrađenoj od prirodnog materijala.

U sva tri slučaja usvojeno je isto saobraćajno opterećenje.

\section{DIMENZIONIRANJE SLOJEVA FLEKSIBILNE KOLOVOZNE KONSTRUKCIJE NA POSTELJICI OD MATERIJALA SPRAVLJENOG PO RECEPTURI (50 \% “CRNO MORE” I 50 \% "BIJELO MORE ")}

Srednja vrijednost modula stišljivosti na posteljici izrađenoj od maetrijala spravljenog po recepturi VIII iznosi $\mathrm{Ms}=22 \mathrm{MPa}$ što odgovara vrijednosti $\mathrm{CBR}=10,63 \%$. Ostali parametri potrebni za dimenzioniranje su usvojeni proizvoljno.

Podaci o prosječnom godišnjem saobraćaju:

\begin{tabular}{|l|l|}
\hline \multicolumn{1}{|c|}{ Vrsta vozila } & \multicolumn{1}{c|}{ Broj vozila } \\
\hline - Automobili & 5000 \\
\hline -Autobusi & 70 \\
\hline -Kamioni: & \\
\hline -laki & 200 \\
\hline -srednji & 100 \\
\hline -teški & 50 \\
\hline -teški sa prikolicom & 20 \\
\hline
\end{tabular}

Tabela 1: Podaci o prosječnom godišnjem saobraćaju

Karakteristike projektovanog puta :

-Širina saobraćajne trake 2x3,0 m, -Trajanje kolovozne konstrukcije 20 god., -Stopa godišnjeg porasta saobraćaja 3\%, -Max. uzdužni nagib 6\%,

$\mathrm{Na}$ osnovu provedenog dimenzioniranja usvojene debljine kolovozne konstrukcije prikazane su na slici 1 . 

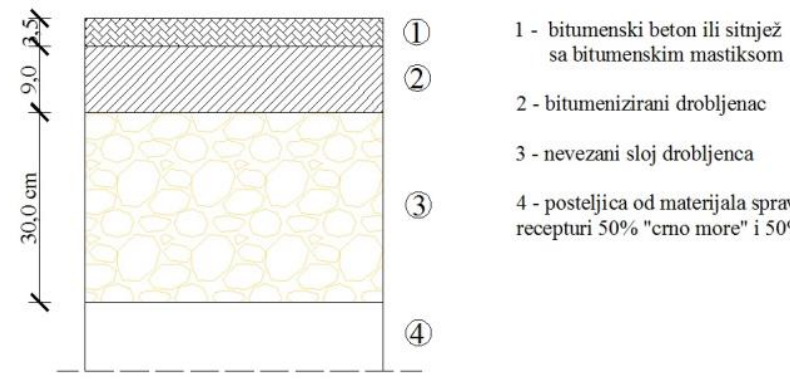

Slika 1. Usvojene debljine slojeva kolovozne konstrukcije

Dubina smrzavanja i hidrološki uslovi imaju različito dejstvo na kolovoznu konstrukciju u različitim klimatskim područjima, te kao takvi nisu razmatrani. [2]

\section{DIMENZIONIRANJE SLOJEVA FLEKSIBILNE KOLOVOZNE KONSTRUKCIJE NA POSTELJICI OD MATERIJALA SPRAVLJENOG PO RECEPTURI (30 \% "CRNO MORE", 40 \% "BIJELO MORE “ I 30 \% KAMENI AGREGAT 0-31,5 MM)}

Srednja vrijednost modula stišljivosti na posteljici izrađenoj od materijala spravljenog po recepturi XI iznosi $\mathrm{Ms}=31 \mathrm{MPa}$ što odgovara vrijednosti $\mathrm{CBR}=13,6 \%$

$\mathrm{U}$ analizi saobraćajnog opterećenja je sračunat broj prolaza nominalnog osovinskog opterećenja (NOO) od $82 \mathrm{kN}$ koji iznosi $\mathbf{T}_{\mathbf{n}}=\mathbf{1 , 5 7} \times \mathbf{1 0}^{\mathbf{6}}$

Provjera debljinskog indeksa kolovozne konstrukcije:

$\mathrm{D}=3,5 \cdot 0,42+9 \cdot 0,35+26 \cdot 0,14=\mathbf{8 , 2 6}>\mathbf{8 , 2 5}$

$\mathrm{Na}$ osnovu provedenog dimenzioniranja usvojene debljine kolovozne konstrukcije prikazane su na slici 2 .

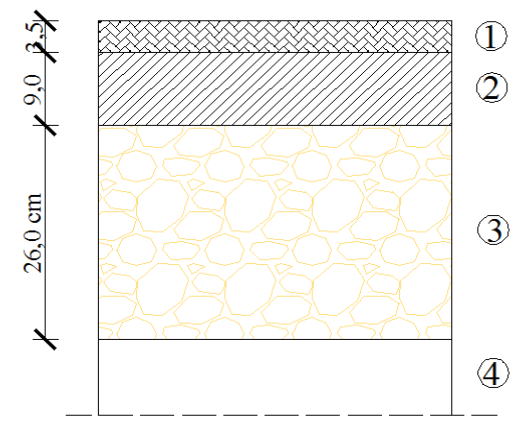

1 - bitumenski beton ili sitnjež sa bitumenskim mastiksom

2 - bitumenizirani drobljenac

3 - nevezani sloj drobljenca

4 - posteljica od materijala spravljenog po recepturi $30 \%$ "crno more", $40 \%$ "bijelo more" i $30 \%$ kameni agregat

Slika 2. Usvojene debljine slojeva kolovozne konstrukcije 
Contemporary achievements in civil engineering 22. April 2016. Subotica, SERBIA

\section{DIMENZIONIRANJE SLOJEVA FLEKSIBILNE KOLOVOZNE KONSTRUKCIJE NA POSTELJICI SREDNJEG KVALITETA IZRAĐENOJ OD PRIRODNOG MATERIJALA}

Na osnovu tabele - klasifikacija posteljice, kao srednja vrijednost posteljice srednjeg kvaliteta uzeta je vrijednost $\mathrm{CBR}=14 \%$. $U$ analizi saobraćajnog opterećenja sračunat je broj prolaza nominalnog osovinskog opterećenja (NOO) od $82 \mathrm{kN}$ koji iznosi $\mathbf{T}_{\mathbf{n}}=\mathbf{1 , 5 7}$ $\mathbf{x} 10^{6}$.

Provjera debljinskog indeksa kolovozne konstrukcije:

$\mathrm{D}=3,5 \cdot 0,42+9 \cdot 0,35+25,5 \cdot 0,14=\mathbf{8 , 1 9}>\mathbf{8 , 1 8}$

$\mathrm{Na}$ osnovu provedenog dimenzioniranja usvojene debljine kolovozne konstrukcije prikazane su na slici 3.

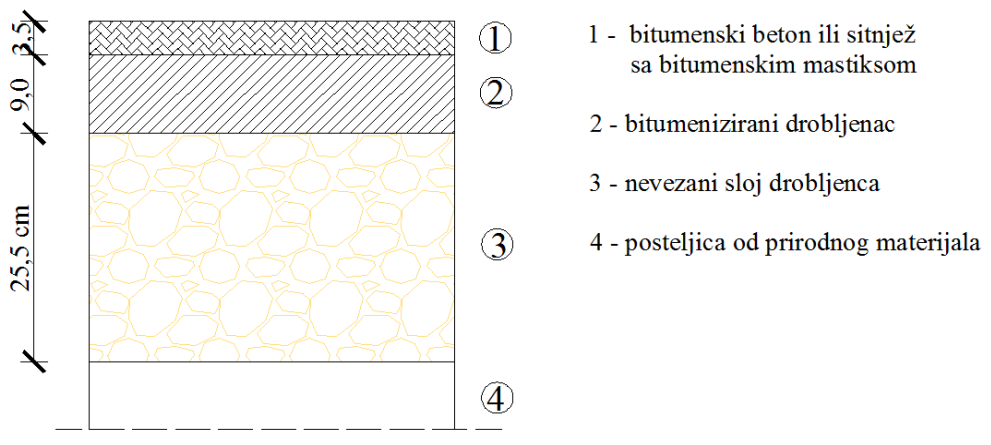

Slika 3. Usvojene debljine slojeva kolovozne konstrukcije

\section{ANALIZA ODNOSA DEBLJINA SLOJEVA KOLOVOZNE KONSTRUKCIJE}

$\mathrm{Na}$ osnovu izvršenih dimenzioniranja kolovozne konstrukcije, a za tri tipa izvedbe donjeg stroja puta daje se grafički prikaz odnosa debljina dimenzioniranih asfaltnih slojeva.

Izvršeno je dimenzioniranje za tri vrste materijala:

1.Kolovozna konstrukcija na posteljici izrađenojod materijala spravljenog po recepturi : 50 \% "crno more" i 50 \% "bijelo more ",

2. Kolovozna konstrukcija na posteljici izrađenoj od materijala spravljenog po recepturi: $30 \%$ "crno more", $40 \%$ "bijelo more " i $30 \%$ kameni agregat 0-31,5 mm,

3.Kolovozna konstrukcija na posteljici srednjeg kvaliteta izrađenoj od prirodnog materijala.

Grafički su prikazani rezultati dimenzioniranja kao odnos debljina pojedinih slojeva kolovozne konstrukcije dobivenih dimenzioniranjem za tri vrste materijala na slikama 4,5 i $6 .[5]$ 
4. МЕЂУНАРОДНА КОНФЕРЕНЦИЈА

Савремена достигнућа у грађевинарству 22. април 2016. Суботица, СРБИЈА

Debljina asfaltnog habajućeg sloja

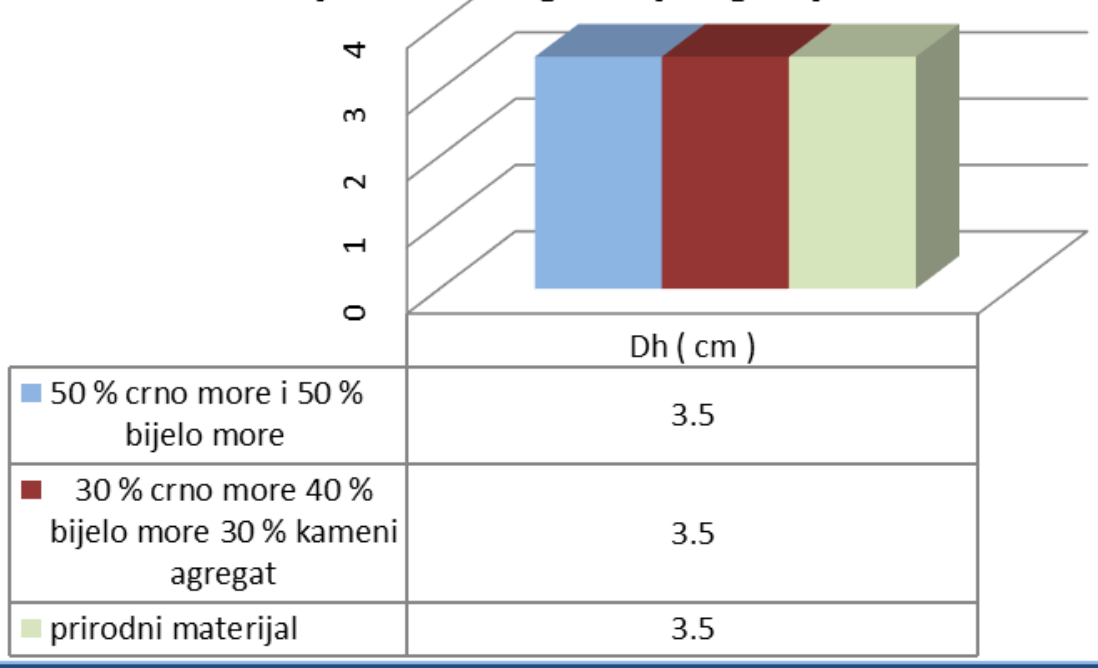

Slika 4. Debljina asfaltnog habajućeg sloja

\section{Debljina asfaltnog gornjeg nosivog sloja}

\begin{tabular}{|c|}
\hline $\begin{array}{c}50 \% \text { crno more i } 50 \% \\
\text { bijelo more }\end{array}$ \\
\hline $\begin{array}{c}30 \% \text { crno more } 40 \% \\
\text { bijelo more } 30 \% \text { kameni } \\
\text { agregat }\end{array}$ \\
\hline prirodni materijal
\end{tabular}

Slika 5. Debljina asfaltnog gornjeg nosivog sloja 


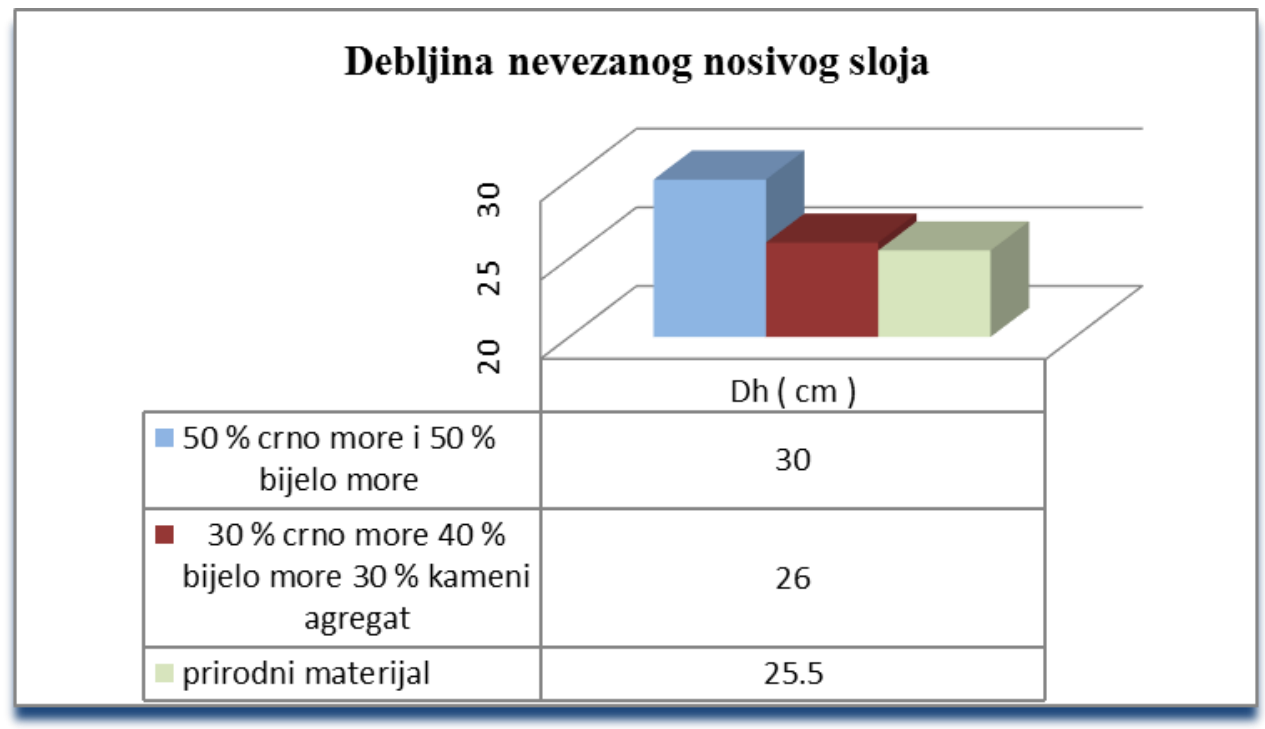

Slika 6. Debljina nevezanog nosivog sloja

\section{ZAKLJUČAK}

Analizom je obuhvaćena izvedba donjeg stroja za tri odabrane recepture. Kolovozne konstrukcije prema važećoj metodi, a koje se izvode na donjem stroju za tri odabrane recepture, dimenzionirane su i analizirane $u$ radu.

Uporednom analizom slojeva fleksibilne konstrukcije zaključuje se sljedeće :

- debljine asfaltnog habajućeg sloja i asfaltnog gornjeg nosivog sloja zavise samo od saobraćajnog opterećenja, te na iste ne utiče vrsta posteljice, s obzirom da smo u sva tri slučaja dobili jednake debljine slojeva,

- na debljinu nevezanog nosivog sloja utiče vrsta odnosno nosivost posteljice,

- najmanju debljinu nevezanog nosivog sloja imala je kolovozna konstrukcija izrađena na posteljici srednjeg kvaliteta od prirodnog materijala, te se kao takva pokazala kao najbolja. Nevezani nosivi sloj na posteljici od materijala spravljenog po recepturi: $50 \%$ "crno more" i $50 \%$ "bijelo more ", imao je za 17,65 \% veću debljinu od onog na posteljici od prirodnog materijala, dok je nevezani nosivi sloj na posteljici od materijala spravljenog po recepturi: $30 \%$ "crno more", $40 \%$ "bijelo more " i $30 \%$ kameni agregat $0-31,5 \mathrm{~mm}$ imao za $1,96 \%$ veću debljinu od onog na posteljici od prirodnog materijala.

- Dubina smrzavanja i hidrološki uslovi nisu razmatrani prilikom dimenzioniranja s obzirom da imaju različito dejstvo na kolovoznu konstrukciju u različitim klimatskim područjima. U područjima sa dubinom smrzavanja manjom od $60 \mathrm{~cm}$ dobiveni rezultati bi ostali isti, dok u područjima sa dubinom smrzavanja većom od $60 \mathrm{~cm}$ došlo bi do promjene debljine nevezanog nosivog sloja, tj. morali bi ga povećati do te debljine da zadovolji uslove za dubinu smrzavanja date u Smjernicama. 
Na bazi rezultata ispitivanja, može se konstatovati da kombinacija materijala krečnog mulja iz „bijelog mora“ i elektrofilterskog pepela, pripremljenih prema datim recepturama može se upotrebljavati za zemljane radove u građevinarstvu koji nisu pod direktnim uticajem vode.

Moguća je upotreba i drugih receptura, ali je neophodno dodatno ispitivanje. Ukoliko se materijal upotrebljava za izradu brana neophodno je obezbijediti vodonepropusni sloj gline ili nekog vještačkog materijala na strani koja je u dodiru sa vodom. Takođe je neophodna izrada drenažnog sistema radi odvođenja procjedne vode, s obzirom da veća količina vode u materijalu smanjuje čvrstoću zbijenog materijala. Važno je naglasiti da materijal iz „bijelog mora“ sadrži veliku količinu vlage, te je neophodno njegovo sušenje prije ugradnje.

\section{LITERATURA}

[1] Elaborat o mogućnostima primjene pepela iz ,,crnog mora“ “ $i$ otpada iz ,, bijelog mora ", Institut za građevinarstvo, građevinske materijale i nemetale d.o.o. Tuzla, Tuzla, 2011.

[2] Smjernice za projektovanje, građenje, održavanje i nadzor na putevima, Knjiga II: Građenje, Dio 2: Posebni tehnički uslovi, Sarajevo/Banja Luka 2005,

[3] Bašić, Z., Džananović A.: Upotreba nusproizvoda procesa proizvodnje sode za izgradnju donjeg stroja puteva, SGIS, Geotehnički aspekti građevinarstva, zbornik radova, 2013, str. 383-390

[4] Mazić, B.; Lovrić, I.: Ceste, Građevinski fakultet Univerziteta u Sarajevu, Sarajevo, 2010.

[5] Hadžić, H.: Uticaj primjene različitih materijala na odabir optimalnog rješenja izgradnje donjeg stroja saobraćajnica, RGGF Univerziteta u Tuzli, 2014.

\section{ANALYSIS OPTIMAL LAYERS OF FLEXIBLE PAVEMENTS}

Summary: In the construction of substructure of roads, the construction of embankments and construction of hydraulic structures, it is necessary to provide quality borrow materials for this purpose. Large industrial plants during production, creating industrial waste that needs to be deposited, and which ultimately requires a large expenses. For this reason, and emerged idea of exploring the possibility of using industrial by-products in the production of soda ash for construction purposes, construction of substructure of roads, embankments and hydro-technical objekata.za needs analysis optimal layers of flexible pavements was carried out research on the model dimensioned according to the current method of dimensioning given in the guidelines for the design, construction, maintenance and control of the roads (book I, part I, of chapter 7). The analysis covered the lower performance of the machine for three selected recipes. Pavement 


\section{$4^{\text {th }}$ inTERnATIONAL CONFERENCE}

Contemporary achievements in civil engineering 22. April 2016. Subotica, SERBIA

according to the current method, which is performed on the lower machine for three selected recipes, dimensioned and analyzed in the paper.

Keywords: undercarriage, analysis, pavement structure, methods, sizing 